\title{
Killer dendritic cells: mechanisms of action and therapeutic implications for cancer
}

\author{
AK Wesa ${ }^{*, 1}$ and WJ Storkus ${ }^{1,2,3}$
}

Dendritic cells (DC) are essential for the development and regulation of adaptive host immune responses against tumors. DC are heterogeneous and comprised of diverse cellular subsets. They are best known for mediating a crucial role in the initiation of acquired immunity by serving as professional antigen presenting cells (APC) that take up antigens in their local microenvironment, which are then processed and presented to naïve $T$ cells in the context of major histocompatibility complex (MHC) class I and II molecules. In addition to these functions, DC can modulate the types of T cell responses they generate, and can also influence the responses of innate effectors, such as NK cells. There is also now evidence that they may mediate a more primordial role as innate, effector cells that are tumoricidal. 'Killer' DC (KDC) may represent a true 'multi-tasking' cell type that can sequentially act as a 'hunter-gatherer' of antigens; as well as, an instructor, then enforcer/regulator, of antigenspecific anti-tumor T-cell responses in vivo. In this review, we will critically examine the published record regarding KDC, their mechanism(s) of action, and then consider the potential integration of KDC into novel immunotherapies for patients with cancer. Cell Death and Differentiation (2008) 15, 51-57; doi:10.1038/sj.cdd.4402243; published online 19 October 2007

\section{Subsets of Natural and Induced KDC}

Killer DC (KDC) have been described in both rodents and humans, with the ability of DC to directly mediate cellular cytotoxicity first reported by Suss et al. ${ }^{1}$ for the $\mathrm{CD} 8 \alpha^{+}$subset of murine splenic DC, where these cells were found competent to induce the apoptotic death of allogeneic $T$ cells through a Fas/Fas ligand-dependent mechanism. ${ }^{1}$ While it has been also suggested that the induction of T-cell apoptosis by $\mathrm{CD} 8 \alpha^{+} \mathrm{DC}$ may represent a mechanism for maintaining peripheral T-cell tolerance in the mouse, this conclusion is clearly controversial, as CD $8 \alpha^{+} \mathrm{DC}$ can also effectively initiate T-cell responses both in vitro and in vivo., ${ }^{2,3}$ Nevertheless, subsequent evaluations indicated that murine bone marrow (BM)-derived DC (BM-DC) were capable of mediating the Fas-dependent apoptosis of a human transformed $\mathrm{T}$ cell line (i.e. Jurkat). ${ }^{4}$ These initial findings that $\mathrm{DC}$ could promote the apoptotic death of primary and transformed T cells (under at least some conditions) served as fuel for subsequent investigations of the comparative ability of DC subpopulations to serve as KDC against tumor cells (Table 1).

One of the first published studies detailing the cytotoxic properties of human DC compared the tumoricidal functions of freshly-isolated, peripheral blood, $\mathrm{CD} 11 \mathrm{c}^{+} \mathrm{DC}$ and pre-DC $\left(\mathrm{CD} 11 \mathrm{C}^{-} \mathrm{IL}-3 \mathrm{R} \alpha^{+}\right) .{ }^{18}$ Following treatment with IFN- $\alpha$ or IFN- $\gamma$,
$\mathrm{CD}_{11 \mathrm{C}^{+}} \mathrm{DC}$, but not IL-3R $\alpha+$ pre-DC, expressed detectable levels of cell surface tumor necrosis factor-related apoptosisinducing ligand (TRAIL) and were able to instigate TRAILdependent apoptosis of a range of human tumor cell lines (Table 2). Another early report suggested that HLA-DR ${ }^{+}$, lineage ${ }^{-}$DC isolated from peripheral blood express detectable levels of TNF family members associated with the ability to mediate apoptosis, such as tumor necrosis factor (TNF), TRAIL, FasL, Lymphotoxin (LT)- $\alpha$, LT $\beta$ on their cell surface. ${ }^{22}$ However, these DC were not directly assessed for their cytolytic reactivity against tumor cells. In more recent studies, freshly-isolated, myeloid-type M-DC8 ${ }^{+} \mathrm{DC}$ (pre-treated with IFN- $\gamma$ ) from the peripheral blood have been shown to promote target cell apoptosis via a mechanism that is at least partially TNF- $\alpha$-dependent. ${ }^{19}$ Interestingly, within the M-DC8 ${ }^{+}$blood DC population, the Fc receptor (CD16 and CD32) ${ }^{+}$subpopulation of KDC, appears capable of mediating antibodycoated target cell death via antibody-dependent cellular cytotoxicity. ${ }^{20}$

In addition to promoting tumor cell death via apoptotic mechanisms, KDC may also inflict necrotic cell death on tumor cells. Thus, human HLA-DR,$+ \mathrm{CD}_{11 \mathrm{c}^{+}}$peripheral blood-derived myeloid $\mathrm{DC}$ (in the presence of toll-like receptor (TLR)-7/8 ligand agonists) express perforin and granzyme B,

\footnotetext{
${ }^{1}$ Department of Dermatology, University of Pittsburgh School of Medicine, Pittsburgh, PA, USA; ${ }^{2}$ Department of Immunology, University of Pittsburgh School of Medicine, Pittsburgh, PA, USA and ${ }^{3}$ University of Pittsburgh Cancer Institute, Pittsburgh, PA, USA

${ }^{*}$ Corresponding author: AK Wesa, Department of Dermatology, University of Pittsburgh School of Medicine, W1045 Biomedical Science Tower, 200 Lothrop Street, Pittsburgh, PA 15213, USA. Tel: + 412648 9983; Fax: + 412383 5857; E-mail: wesaak@upmc.edu

Keywords: dendritic cells (DC); cytotoxicity; apoptosis; tumor cells; killer cells

Abbreviations: ADCC, antibody-dependent cellular cytotoxicity; BM-DC, bone marrow-derived DC; CFSE, 5-(and -6)-carboxyfluorescein diacetate succinimidyl ester; DC, dendritic cell; IFN, interferon; IKDC, interferon-producing killer DC; iNOS, inducible nitric oxide synthase; KDC, killer DC; LCMV, lymphocytic choriomeningitis virus; LT, lymphotoxin; MDC, myeloid DC; Mono-DC, monocyte-derived DC; NK, natural killer; NKDC, natural killer DC; ODN, oligodeoxynucleotides; pDC, plasmacytoid DC; TLR, toll-like receptor; TNF, tumor necrosis factor; TRAIL, tumor necrosis (TNF)-related apoptosis-inducing ligand

Received 18.7.07; revised 20.8.07; accepted 28.8.07; Edited by G Kroemer; published online 19.10.07
} 


\begin{tabular}{|c|c|c|c|c|c|c|c|}
\hline \multirow[b]{2}{*}{ Subset/phenotype } & \multirow[b]{2}{*}{ Rat/mouse } & \multirow[b]{2}{*}{$\begin{array}{l}\text { Stimulators of DC } \\
\text { cytolytic activity }\end{array}$} & \multirow[b]{2}{*}{$\begin{array}{l}\text { Mechanism of } \\
\text { target cell death }^{a}\end{array}$} & \multicolumn{3}{|c|}{ Targets } & \multirow[b]{2}{*}{ Ref. } \\
\hline & & & & T cells & $\begin{array}{l}\text { NK } \\
\text { sensitive } \\
\text { lines }\end{array}$ & $\begin{array}{l}\text { Tumor } \\
\text { cell lines }\end{array}$ & \\
\hline Spleen, CD8 $\alpha^{+}$ & $\mathrm{M}$ & None $^{b}$ & FasL & + & & & 1 \\
\hline Epidermal Langerhans cells & $\mathrm{M}$ & $\begin{array}{l}\text { Anti-CD40 (not LPS } \\
\text { IFN- } \gamma \text { ) }\end{array}$ & FasL & + & & & 5 \\
\hline Spleen, CD4- ${ }^{-} \mathrm{OX} 62^{+}$ & $\mathrm{R}$ & None & $\begin{array}{l}\text { (Not FasL. Not } \\
\text { TRAIL, not TNF) }\end{array}$ & & + & & 6 \\
\hline $\begin{array}{l}\text { Lymph node, CD4 }{ }^{-} \mathrm{CD}_{103^{+}} \\
\mathrm{CD}^{2} 00^{+} \mathrm{MHC} \text { class } \mathrm{II}^{\mathrm{lo}}\end{array}$ & $\mathrm{R}$ & None & $\begin{array}{l}\text { (Not FasL, not } \\
\text { caspase } \\
\text { dependent) }\end{array}$ & & & + & 7 \\
\hline $\begin{array}{l}\text { Spleen } \mathrm{CD} 103^{+} \mathrm{CD}^{+} 6^{+} \mathrm{MHC} \\
\text { class } \mathrm{II}^{+}\end{array}$ & $\mathrm{R}$ & Anti-NKR-P2 & Nitric oxide & & + & + & 8,9 \\
\hline BM-derived & $\mathrm{R}$ & $\begin{array}{l}\text { Anti-NKR-P2, LPS, } \\
\text { IFN- } \gamma\end{array}$ & Nitric oxide & & & + & 9,10 \\
\hline BM-derived & M & None & FasL & + & & & 4 \\
\hline BM-derived & $\mathrm{M}$ & None & Nitric oxide & & & + & 9,11 \\
\hline BM-derived & $M$ & Ad-IL-12 Ad-IL-18 & TNF, TRAIL & & & + & 12 \\
\hline BM-derived & M & None & FasL, TRAIL, TNF & & & + & 13 \\
\hline $\begin{array}{l}\text { Spleen NKDC: all } \\
\text { CD11 }^{+} \mathrm{CD}^{4} 4 \mathrm{~b}^{+}\end{array}$ & M & LCMV+anti-CD40 & ? & & + & & 14 \\
\hline $\begin{array}{l}\text { Spleen NKDC: all } \\
\text { CD } 11 c^{+} \mathrm{NK} 1.1^{+}\end{array}$ & M & & $?$ & & + & & 15 \\
\hline $\begin{array}{l}\text { C57Bl/6 spleen IKDC: CD11c } \\
{\mathrm{B} 220^{+}}^{+} \mathrm{NK}^{+} .1^{+}{\text {Ly } 6 \mathrm{c}^{-}}^{-}\end{array}$ & M & & TRAIL & & + & & 16 \\
\hline 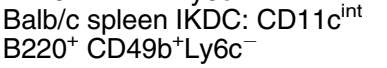 & $\mathrm{M}$ & CpG & $?$ & & + & & 17 \\
\hline
\end{tabular}

aMechanisms demonstrated to be involved (or excluded) to have a role in target killing. ' $'$ None' indicates activity is spontaneous

Table 2 Cytolytic activity of DC subsets in humans

\begin{tabular}{|c|c|c|c|}
\hline Subtype & Enhancers of cytolysis & Mechanisms involved & Ref. \\
\hline 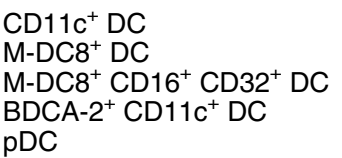 & $\begin{array}{l}\text { IFN- } \alpha, \text { IFN- } \gamma \\
\text { IFN- } \gamma \\
\text { CD16, CD32 engagement } \\
\text { TLR7/8 ligand (Imiquimod) } \\
\text { TLR7/8 ligand (Imiquimod) }\end{array}$ & $\begin{array}{l}\text { TRAIL (not TNF, not FasL) } \\
\text { TNF- } \alpha \\
\text { ADCC, TNF- } \alpha \\
\text { Perforin, granzyme B } \\
\text { TRAIL }\end{array}$ & $\begin{array}{l}18 \\
19 \\
20 \\
21 \\
21\end{array}$ \\
\hline
\end{tabular}

and serve as potent KDC against the chronic myelogenous leukemia cell line K562, but not the Jurkat T cell line (known to be refractory to perforin/granzyme-mediated death) ${ }^{21}$ Curiously, while human plasmacytoid DC (pDC) express intracellular granzyme B constitutively, TLR7 ligand engagement on pDC results in the ability of these cells to mediate apoptosis of Jurkat cells via a TRAIL-dependent mechanism, but not K562 cells which are resistant to TRAIL-induced apoptosis. ${ }^{21}$ These findings suggest that freshly-isolated human DC subsets isolated from the peripheral blood require some form of activation (i.e pro-inflammatory signals provided by IFNs, TLR ligands, among others) to upregulate effector molecule expression associated with optimal anti-tumor KDC function implementing the apoptotic and/or necrotic pathways. This dependency on activation for KDC functionality may serve as a safe-guard against untoward cytotoxicity directed against normal or immunologically-beneficial (i.e. effector/memory T cells).

Natural KDC have also been identified in mice; and similar to human $\mathrm{DC}$, the pre-activation of $\mathrm{DC}$ is generally required for these cells to mediate cytotoxicity against target cells (Table 1). For instance, in mice, epidermal Langerhans cells are known to upregulate their cell-surface expression of FasL after activation with CD40 ligand, resulting in their ability to kill Jurkat cells via apoptosis. ${ }^{5}$ We were unable to identify any published reports of tumor killing induced by conventional myeloid DC (mDC; $\left.\quad \mathrm{CD}_{11 \mathrm{~b}}{ }^{+} \mathrm{CD} 11 \mathrm{c}^{+}\right)$or $\mathrm{pDC}$ $\left(\mathrm{CD} 11 \mathrm{c}^{+} \mathrm{CD}_{11 \mathrm{~b}}-\mathrm{B} 220^{+} \mathrm{Gr}^{+}{ }^{+}\right)$subsets. ${ }^{23-25}$ Hence, it remains unclear whether these DC subsets exhibit this property spontaneously, or if they must be induced to acquire it.

On the other hand, a novel murine subset of splenic DC was recently identified, and coined 'natural killer DC' (NKDC). ${ }^{14,15}$ These cells have overlapping characteristics of both cytolytic effector cells and professional antigen presenting cells (APC) (i.e. they possess phenotypic and functional properties consistent with NK cells and DC; see review by Spits and Lanier $^{26}$ ). NKDC undergo rapid expansion in vivo during lymphocytic choriomeningitis virus (LCMV) infection and secrete IFN- $\gamma{ }^{14}$ A subset of the heterogeneous NKDC population has been described as interferon-producing killer DC (IKDC) ${ }^{16,17}$ (recently reviewed in Shortman and Villadangos ${ }^{27}$ ), recognized on the basis of a CD11 ${ }^{+} \mathrm{B}_{22}{ }^{+}$ $\mathrm{NK} 1.1^{+} \mathrm{CD} 49 \mathrm{~b}^{+} \mathrm{Ly}_{6 \mathrm{c}^{-}}$phenotype. These cells secrete IFNs and have NK-like cytotoxicity (dependent in part upon NKG2D) in addition to APC function. ${ }^{17}$ IKDC cells do not spontaneously express major histocompatibility complex (MHC) Class II, but 
acquire it upon exposure to stimuli such as tumor cells. ${ }^{28}$ In response to the TLR9 ligands, NKDC/IKDC can secrete IFN- $\alpha$, IFN- $\gamma$ and IL-12 $15,17,29$ while in response IL-12 and IL-18 or tumors, these cells secrete high levels of IFN- $\gamma .^{16,29,30}$ IFNs may mediate a feedback loop, resulting in the upregulation of TRAIL by these DC, which is required for the observed killing of NK-resistant targets by IKDC. In contrast, CpG ODNs appear to promote NKG2D-dependent cytotoxicity of NKsensitive targets (as well as RAE1 + transfectants) by IKDC. A true counterpart to the murine NKDC/IKDC population has yet to be identified in humans; however, an IL-18-induced NK subpopulation that coexpresses at least some DC markers (i.e. CD83) has been described. ${ }^{31}$ Further, there is evidence supporting the instructive crosstalk between NK and DC, ${ }^{32}$ that could spawn such tumoricidal KDC.

In rats, a DC subset identified in freshly isolated spleen or lymph nodes (bearing a CD4 ${ }^{-}, \mathrm{OX}^{+} 2^{+}\left(\mathrm{CD} 103^{+}\right), \mathrm{CD} 200^{+}$ phenotype) has been reported to promote the apoptotic death of NK-sensitive and NK-resistant tumor cell lines, but not T cells. ${ }^{6,7}$ Unexpectedly, the underlying mechanism of cytotoxicity appears independent of Fas/FasL, TRAIL, TNF and caspase, ${ }^{6,7}$ and is ablated upon DC maturation. Notably, following the apoptosis of tumors, KDC were observed to ingest dying 5- (and -6)-carboxyfluorescein diacetate succinimidyl ester (CFSE)-labeled target cells as assessed by flow cytometry and confocal microscopy, ${ }^{7}$ providing a potential substrate for specific T-cell stimulation. An independent group has similarly reported that rat $\mathrm{CD} 103^{+} \mathrm{KDC}$ may be activated via NKR-P2 signaling (the rat ortholog of mouse NKG2D), with an agonist antibody against NKR-P2 demonstrated to augment KDC tumoricidal function in vitro and to delay tumor growth in vivo. ${ }^{8,9}$ In contrast to prior studies performed on human and mouse $\mathrm{KDC}$, these rat KDC mediate tumor cell death through a mechanism dependent upon nitric oxide (NO) production. $^{9}$ This does not rule out the possibility that additional pathways may be coutilized for optimal KDC function, or that additional activating factors/conditions may induce rat KDC to acquire TNF-family member- or perforin/ granzyme-dependent mechanisms for promoting tumor cell death. Indeed, the NO-dependency of KDC lysis observed by Srivastava et al. $^{9}$ may reflect the reported ability of NO to sensitize tumor cell targets to apoptosis mediated by KDC via Fas, etc. $^{13}$

\section{Cultured KDC Generated from Bone Marrow Progenitor Cells or Monocytes}

Due to the logistical limitations imposed by the relative rarity of DC subpopulations in vivo, many have turned to analyses of DC generated from precursor populations in vitro. Despite the obvious caveats associated with the physiologic relevance of a given cultured DC population, these cells can be produced in large numbers for modeling purposes and may represent a platform for the development of therapeutic DC-based vaccines and therapies for cancer patients.

Studies of BM-DC in rodents have given further insights into the killing properties of DC. Interestingly, it appears that such in vitro generated DC exhibit most potent cytotoxic potential after undergoing 'spontaneous' maturation (occurring over time in the absence of known exogenous activators). ${ }^{13}$ TNF family members including FasL, TRAIL and TNF- $\alpha$ are expressed by cultured immature and spontaneously-matured $\mathrm{BM}-\mathrm{DC},{ }^{4,13}$ allowing these KDC to promote the apoptosis of human Jurkat cells and the murine A20 B cell lymphoma, with Fas- $L$ (-/-) DC proving inferior in KDC function. ${ }^{13}$ Furthermore, transduction of BM-DC with adenovirus constructs encoding mIL-12p70 and mIL-18 leads to enhanced TNF- $\alpha$ and TRAIL expression and improved KDC function against syngenic CMS4 sarcoma cells. ${ }^{12}$ As previously mentioned, NO appears to represent yet another lytic agent, or (at least) a sensitizer of tumor cells to cytotoxicity mediated by both rodent KDC. $9,10,11,13$

Human DC generated in vitro from monocyte (mono-DC) precursors have also been reported to kill various tumor cell lines in the absence of overt exogenous stimuli (Table 3). ${ }^{19,22,33,34,36}$ The specific mechanism(s) by which these DC promote the demise of tumor cells remains highly controversial, with numerous examples of directly conflicting reports. For example, Vanderheyde et al. ${ }^{33}$ reported that monoDC killing occurred independently of DC expressed TNF, FasL or TRAIL, since specific blocking antibodies or soluble fusion proteins did not antagonize the ability of these cells to induce tumor cell apoptosis. However, Lu et al. ${ }^{22}$ reported that all three of these TNF-family members, in addition to LT- $\alpha$ and LT- $\beta$, are responsible for the observed cumulative tumoricidal activity exhibited by DC (i.e. specific, single antagonists for each TNF family member molecule provided only incremental inhibition of KDC activity, while the combined use of all inhibitors effectively ablated DC-mediated killing).

In general, the cytolytic capacity of cultured human monoDC is enhanced by certain activation stimuli, although these need not represent conventional maturation factors. ${ }^{36}$ Crosslinking of CD40 molecules (using rhCD40L) expressed by DC enhances the ability of these APC to inhibit the growth of tumor cell lines via a (TNF- $\alpha$-dependent) apoptotic mechanism in coculture experiments. ${ }^{37,38}$ As a cautionary note, however, a number of carcinomas (cell lines and tissue specimens) may themselves express CD40, and the growth and survival of these tumor cell lines can be inhibited directly by rhCD40L. ${ }^{44,45}$ This may suggest that at least some of the KDC anti-tumor effects observed by Joo et al. ${ }^{37}$ may be KDC-independent.

Table 3 Mechanisms of cytolytic activity of in vitro generated human DC

\begin{tabular}{lllr}
\hline Mechanisms & Enhancers of cytolysis & Targets & Ref. \\
\hline Unidentified & None $^{\mathrm{a}}$ & Tumor lines, Jurkat & $19,33-35$ \\
TNF & None, CD40L & Tumor lines & $22,36-38$ \\
TRAIL & None, dsRNA, IFN- $\beta$, IFN- $\gamma$ (not LPS) & Tumor lines (but not Jurkat and not normal neonatal cells) \\
FasL & None Maturation+Ad-FasL & Tumor lines, Jurkat, activated T cells & $22,36,38-40$ \\
\hline
\end{tabular}

a'None' indicates DC demonstrated killing in absence of additional treatment 
Whether human mono-DC spontaneously express FasL and can mediate FasL-dependent killing also remains controversial. With few exceptions, ${ }^{22,41}$ most studies have failed to implicate FasL in DC-dependent tumor killing, 33,37,38,42,43 although forced overexpression of FasL in DC (via adenoviral transduction) conferred the ability to kill Fas ${ }^{+}$Jurkat cells in vitro. $^{42}$ This is consistent with analyses of freshly-isolated human DC subsets, where FasL does not appear to play a significant role in tumor cell killing. Equivocal data also exists for the role of TRAIL in human DC-mediated killing. For instance, TRAIL expression has been reported to be readily upregulated on mono-DC using TLR ligands (i.e. doublestranded RNA or LPS) or IFN- $\beta$, in association with improved KDC function. However, this has only been observed in some,$^{38,39}$ but not all investigations. ${ }^{33}$

Ex vivo DC generated from sources other than peripheral blood monocytes have also been reported to promote the apoptosis of tumor cells. Ascitic monocytes from ovarian cancer patients that are cultured to become mono-DC acquire the ability to kill both autologous and allogeneic ovarian carcinoma cell lines in vitro via a FasL-dependent mechanism. ${ }^{41}$ Cord blood-derived mono-DC stimulated with IFN- $\gamma$ can kill the Jurkat ( $T$ lymphoma) and HL-60 (myelomonocytic leukemia) tumor cell lines, but not Daudi (Burkitt's lymphoma), tumor cell lines. However, when stimulated with LPS, these DC kill the Daudi and Jurkat, but not the HL-60, target cells. ${ }^{40}$ Both treatments appear to upregulate DC expression of intracellular TRAIL with little effect on TNF or FasL, although the functional role of these TNF family members in tumor cell killing by DC was not investigated. CD34 ${ }^{+}$progenitor cellderived DC express TRAIL, which can be enhanced by both LPS and IFN- $\beta$, and play an, at least, partial role in the DCinduced apoptotic death of hematopoietic tumor cell lines. ${ }^{39}$

At present, it is not clear why a relatively homogenous population such as mono-DC (generated under a standardized culture protocol using rhGM-CSF and rhlL-4 from peripheral blood mononuclear cells) exhibits such diversity with regard to constitutive or induced ability to kill tumor cells and the relevant underlying mechanisms involved in their KDC effector function. However, there appears to be a general consensus that ex vivo generated DC can kill tumor cells in vitro, similar to findings reported for fresh isolates of human DC. Like murine BM-DC, multiple, concerted mechanisms appear to be employed by human mono-DC to initiate tumor cell death (although there have not yet been any reports supporting a role for NO in tumor cell killing by human DC). Interestingly, cultured murine and human DC appear competent to kill tumor cells in the absence of additional activating signals, in contrast to their in vivo counterparts. This may suggest that KDC function is tightly-regulated in vivo.

\section{DC-Mediated Tumoricidal Activity In Vivo}

The evidence for physiological relevance of DC cytotoxicity in vivo remains somewhat circumstantial. In patients undergoing treatment for basal cell carcinoma with the TLR7 agonist Imiquimod, both $\mathrm{mDC}$ and $\mathrm{pDC}$ appear to colocalize near dead/dying tumor cells in situ. ${ }^{21}$ Both tumor-infiltrating DC (TIDC) subsets express granzyme $B$ and TRAIL within lesions, and myeloid DC additionally express perforin, TNF and inducible NO synthase (iNOS; with only trace levels of FasL detected). ${ }^{21}$ This suggests that human TIDC, when activated appropriately, may contribute to tumor cell death (and the consequent cross-priming of anti-tumor $\mathrm{T}$ cells in tumor-draining lymph nodes), although direct proof has not yet been provided. While the demonstration of direct DCmediated killing of tumor cells in vivo is a technically daunting agenda, intra-tumoral injection of DC or treatment of tumors with DC-activating factors has been shown to correlate with reduced tumor growth and even regression. $9,10,12,21,35,46$ Clearly such anti-tumor activity could prove the result of KDC activity, but it could equally well involve DC-induced tumoristatic/antiangiogenic properties ${ }^{34,43}$ and/or the ability of lesion associated DC to activate effector NK and T cells that could themselves mediate tumor cell death. ${ }^{32}$ Studies of DCmediated tumor apoptosis in T/NK-deficient hosts could prove instrumental in visualizing direct killing of tumor cells in situ by DC; although it is likely that tumor regression would not be observed under these conditions, since both T and NK would likely be required for complete tumor eradication. This does not diminish the potential importance of KDC activity in the afferent aspects of anti-tumor immunity (i.e. improved crosspriming of tumor-specific $\mathrm{T}$ cells).

\section{Crosspriming of Anti-Tumor Immunity by KDC}

DC can acquire tumor antigens through a range of uptake mechanisms including fluid-phase or receptor-mediated uptake of soluble antigens released from necrotic tumor cells, ${ }^{47}$ active piracy of living tumor cell membrane components, ${ }^{48}$ as well as, by phagocytosis and receptor-mediated internalization of apoptotic tumor bodies and necrotic tumor debris. ${ }^{49}$ All of these mechanisms provide DC with tumor antigen substrates that may be processed and presented in the context of $\mathrm{MHC}$ molecules for recognition by cognate $\mathrm{T}$ cells in the tumor-bearing host (Figure 1). Indeed, there is preclinical evidence that subsequent to DC-mediated lysis of target cells, these APC engulf antigens from tumor apoptotic bodies, enabling them to cross-prime T-cell responses. ${ }^{7,13,41}$

\section{Therapeutic Implications for KDC}

While formal proof is lacking, if the same cell that kills the tumor takes up the apoptotic body and presents its derivative antigens to $T$ cells in secondary lymphoid organs, the potential convergence of these varied functions in KDC would yield a physiologically-economical/efficient anti-tumor paradigm attractive for clinical translation in the cancer setting. In the context of such a paradigm, two major forms of KDC clinical trials could be immediately envisioned: 1) approaches utilizing ex vivo generated KDC injected into accessible tumor lesions or that would predictably home into tumor lesions after systemic administration; or 2) treatment of cancer patients with modalities that augment KDC function in vivo, particularly within the tumor microenvironment. Each of these strategies could be combined with additional modalities that sensitize tumors to KDC-mediated cell death and/or sustain KDC function within the hostile confines of cancer lesion.

The consideration of developing 'super'-KDC ex vivo for intra-tumoral administration is made more attractive by 


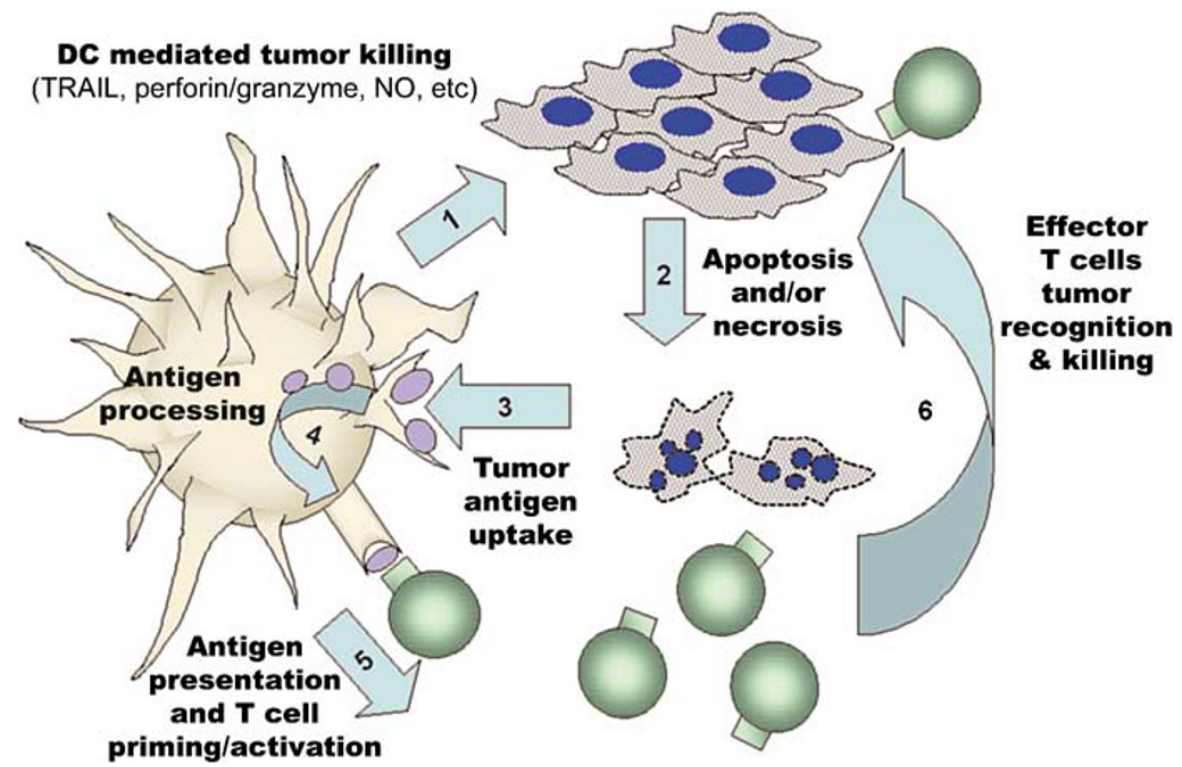

Figure 1 Model of KDC-mediated anti-tumor activity. Following an encounter of KDC with tumor cells (1), tumor cells undergo death via apoptosis or necrosis (2). These dying tumor cells provide antigens for DC uptake, (3) which are then processed into peptides and loaded into MHC molecules (4). DC may then present epitopes from tumor antigen in the context of MHC Class I and Class II molecules to prime and activate specific tumor-reactive T cells (5) leading to the development of effector T cells that can recognize tumors (6) causing tumor lysis and death (2), further diminishing the tumor burden (and contributing an additional pool of antigen for DC uptake)

reports of site-specific tumor regression in patients with metastatic breast cancer or melanoma after injection of autologous $\left(\mathrm{FasL}^{+}, \mathrm{IFN}-\alpha^{+}\right.$) DC into tumor lesions. ${ }^{46}$ The overexpression of TNF-family members by adenoviral transduction $^{42}$ or modulators known to at least transiently increase the expression of these molecules on human DC could yield improved KDC with greater clinical efficacy. Still, the inability of adoptively transferred DC to mediate distal tumor shrinkage, even in cases where the primary lesion (into which DC were injected) exhibits resolution, suggests that additional biological response modifiers may need to be integrated into combinational approaches to fortify and sustain tumorspecific immunity that may be prompted by KDC in vivo.

Therapies designed to promote the infiltration of tumor lesions by KDC to mediate the 'immunogenic death' of tumor cells is logistically more attractive than ex vivo approaches for clinical implementation. Support for the potential success of this strategy may be suggested by current clinical trials implementing the TLR7 ligand, Imiquimod, for the treatment of cutaneous basal cell carcinoma. This therapy enhances DC recruitment into tumor lesions, and increases tumor apoptosis in situ, possibly through the in vivo activation of KDC. ${ }^{21}$ In addition, NKDC/IKDC have been shown to cause tumor regression in vivo. Therapeutic responses mediated by Gleevec and IL-2 in the B16F10 experimental model of melanoma metastasis have been shown to involve TRAIL expressed on IKDC. ${ }^{16,35}$ Similarly, CpG + IL-18 treatment to prevent B16-F10 lung metastases appears to be mediated by $\mathrm{NKDC},{ }^{29}$ as the depletion of these cells eliminates therapeutic efficacy, while the adoptive transfer of $\mathrm{CpG}+\mathrm{IL}-18$ activated NKDC protects against lung metastases. Flt-3 ligand and GMCSF have been used to expand systemic DC populations in both humans and mice. However, in mice, IKDC are preferentially expanded in vivo by $\mathrm{CpG},{ }^{15,17}$ Flt-3 ligand ${ }^{50}$ (or during viral infection ${ }^{14}$ ). In the event that a human equivalent of murine NKDC/IKDC is identified, factors supporting their expansion and sustained functionality in vivo should receive considerable clinical attention.

With regard to sensitizing tumors to KDC-mediated killing in situ, as a means to improve the efficacy of either ex vivo or in vivo KDC therapy approaches, we have recently shown that NO pretreatment of tumors enhances their sensitivity to DCmediated cytotoxicity involving multiple TNF family members (i.e. including TRAIL, TNF- $\alpha$ and FasL).$^{13}$ NO itself did not directly promote tumor cell death, but rather reduced the expression of an anti-apoptotic protein (i.e. survivin) in treated tumor cells, ${ }^{13}$ making them more prone to KDC-induced apoptosis. Application of alternate pre-sensitizers including chemotherapy, radiotherapy or gene therapy (to promote the specific knockdown of anti-apoptotic proteins in tumor cells) could dramatically improve the (systemic rather than locoregional) clinical benefits associated with KDC-based therapies.

Finally, one could consider therapy modifications that would result in sustained KDC survival (i.e. making them more resistant to self-inflicted or tumor-induced apoptosis) ${ }^{42,51,52}$ and functionality (i.e. preventing tumor-induced deviation/ suppression) in cancer patients. Coadministration of TLR agonists (i.e. Imiquimod, CpG ODN), CD40 ligand or cytokines, such as IL-12p70, may not only enhance DC survival, ${ }^{51-54}$ but coordinately bolster KDC cytolytic potential.

\section{Conclusions and Future Directions}

In addition to their pre-eminent role as a master regulator of adaptive immunity mediated via their APC functions, ${ }^{55}$ DC may exert a more primitive, innate immune effector cell function, namely the ability to kill aberrant (tumor) cells. 
Consistent with the 'plasticity' associated with DC differentiation potential, KDC appear competent to promote tumor cell death via a broad array of killing mechanisms, including those linked to apoptotic and necrotic death. Current opinions diverge with regard to which mechanism(s) may be more dominant for a given DC subpopulation or for DC conditioned in specific ways (i.e. in inflammatory or tumor-microenvironmental states). Such controversy may merely suggest that DC employ multiple, coordinate mechanisms (i.e. TNF family members, grazyme/perforin, NO) to induce tumor cell death. Under such conditions, pleiotropy in KDC mechanisms of action provide a safe-guard against evolving, progressor tumor lesions containing a population of cells that are heterogeneous with regard to their sensitivity to the various death pathways. Clearly, the ability of KDC (delivered into the tumor microenvironment via adoptive transfer or by the conditioning or recruitment of endogenous cells into cancer lesions in vivo) to generate an antigenic substrate that they are competent to then uptake and process into $\mathrm{MHC}$ presented epitopes, is logistically attractive in the development of afferent anti-tumor immunity and/or the potentiation of efferent immunity within the tumor microenvironment. Based on the complex and often dysfunctional immunobiology of cancer-bearing hosts, however, the translational integration of $\mathrm{KDC}$ in prospective immunotherapies will likely require the development of combinational approaches. Such strategies should consider concomitant means to increase tumor cell sensitivity to $\mathrm{KDC}$, to modulate the functional polarization of KDC-induced immunity and/or to extend effector KDC and T-cell functionality in vivo.

Acknowledgements. We thank Drs. Adriana Larregina and William Chambers for their careful review of this article. This work was supported by National Institutes of Health Grants R01 CA57840 and P01 CA109688 (both to WJS)

1. Suss G, Shortman K. A subclass of dendritic cells kills CD4 T cells via Fas/Fas-ligandinduced apoptosis. J Exp Med 1996; 183: 1789-1796.

2. Pulendran B, Smith JL, Caspary G, Brasel K, Pettit D, Maraskovsky E et al. Distinct dendritic cell subsets differentially regulate the class of immune response in vivo. Proc Natl Acad Sci USA 1999; 96: 1036-1041.

3. Maldonado-Lopez R, De Smedt T, Pajak B, Heirman C, Thielemans K, Leo O et al. Role of CD8alpha+ and CD8alpha- dendritic cells in the induction of primary immune responses in vivo. J Leukoc Biol 1999; 66: 242-246.

4. Lu L, Qian S, Hershberger PA, Rudert WA, Lynch DH, Thomson AW. Fas ligand (CD95L) and $B 7$ expression on dendritic cells provide counter-regulatory signals for $T$ cell survival and proliferation. J Immunol 1997; 158: 5676-5684.

5. Shibaki A, Katz SI. Activation through CD40 ligation induces functional Fas ligand expression by Langerhans cells. Eur J Immunol 2001; 31: 3006-3015.

6. Trinite B, Voisine C, Yagita H, Josien R. A subset of cytolytic dendritic cells in rat. J Immunol 2000; 165: 4202-4208.

7. Trinite B, Chauvin C, Peche H, Voisine C, Heslan M, Josien R. Immature CD4- CD103+ rat dendritic cells induce rapid caspase-independent apoptosis-like cell death in various tumor and nontumor cells and phagocytose their victims. J Immunol 2005; 175: 2408-2417.

8. Alli R, Savithri B, Das S, Varalakshmi C, Rangaraj N, Khar A. Involvement of NKR-P2/ NKG2D in DC-mediated killing of tumor targets: indicative of a common, innate, targetrecognition paradigm? Eur J Immunol 2004; 34: 1119-1126.

9. Srivastava RM, Varalakshmi C, Khar A. Cross-linking a mAb to NKR-P2/NKG2D on dendritic cells induces their activation and maturation leading to enhanced anti-tumor immune response. Int Immunol 2007; 19: 591-607.

10. Nicolas A, Cathelin D, Larmonier N, Fraszczak J, Puig P-E, Bouchot A et al. Dendritic cells trigger tumor cell death by a nitric oxide-dependent mechanism. J Immunol 2007; 179: 812-818.
11. Shimamura $\mathrm{H}$, Cumberland $\mathrm{R}$, Hiroishi $\mathrm{K}$, Watkins SC, Lotze MT, Baar J. Murine dendritic cell-induced tumor apoptosis is partially mediated by nitric oxide. J Immunother (1997) 2002; 25: 226-234.

12. Tatsumi T, Huang J, Gooding WE, Gambotto A, Robbins PD, Vujanovic NL et al. Intratumoral delivery of dendritic cells engineered to secrete both interleukin (IL)-12 and IL18 effectively treats local and distant disease in association with broadly reactive Tc1-type immunity. Cancer Res 2003; 63: 6378-6386.

13. Huang J, Tatsumi T, Pizzoferrato E, Vujanovic N, Storkus WJ. Nitric oxide sensitizes tumor cells to dendritic cell-mediated apoptosis, uptake, and cross-presentation. Cancer Res 2005; 65: 8461-8470.

14. Homann D, Jahreis A, Wolfe T, Hughes A, Coon B, van Stipdonk MJ et al. CD40L blockade prevents autoimmune diabetes by induction of bitypic NK/DC regulatory cells. Immunity 2002; 16: 403-415.

15. Pillarisetty VG, Katz SC, Bleier JI, Shah AB, Dematteo RP. Natural killer dendritic cells have both antigen presenting and lytic function and in response to $\mathrm{CpG}$ produce IFN-gamma via autocrine IL-12. J Immunol 2005; 174: 2612-2618.

16. Taieb J, Chaput N, Menard C, Apetoh L, Ullrich E, Bonmort M et al. A novel dendritic cell subset involved in tumor immunosurveillance. Nat Med 2006; 12: 214-219.

17. Chan CW, Crafton E, Fan HN, Flook J, Yoshimura K, Skarica M et al. Interferon-producing killer dendritic cells provide a link between innate and adaptive immunity. Nat Med 2006; 12: 207-213

18. Fanger NA, Maliszewski CR, Schooley K, Griffith TS. Human dendritic cells mediate cellular apoptosis via tumor necrosis factor-related apoptosis-inducing ligand (TRAIL). J Exp Med 1999; 190: 1155-1164.

19. Schmitz M, Zhao S, Deuse Y, Schakel K, Wehner R, Wohner H et al. Tumoricidal potential of native blood dendritic cells: direct tumor cell killing and activation of NK cell-mediated cytotoxicity. J Immunol 2005; 174: 4127-4134.

20. Schmitz M, Zhao S, Schakel K, Bornhauser M, Ockert D, Rieber EP. Native human blood dendritic cells as potent effectors in antibody-dependent cellular cytotoxicity. Blood 2002 100: 1502-1504.

21. Stary G, Bangert C, Tauber M, Strohal R, Kopp T, Stingl G. Tumoricidal activity of TLR7/8activated inflammatory dendritic cells. J Exp Med 2007; 204: 1441-1451.

22. Lu G, Janjic BM, Janjic J, Whiteside TL, Storkus WJ, Vujanovic NL. Innate direct anticancer effector function of human immature dendritic cells. II. Role of TNF, lymphotoxinalpha(1)beta(2) Fas ligand, and TNF-related apoptosis-inducing ligand. J Immunol 2002 168: $1831-1839$.

23. Nakano H, Yanagita M, Gunn MD. CD11c(+)B220(+)Gr-1(+) cells in mouse lymph nodes and spleen display characteristics of plasmacytoid dendritic cells. J Exp Med 2001; 194 1171-1178.

24. Bjorck P. Isolation and characterization of plasmacytoid dendritic cells from Flt3 ligand and granulocyte-macrophage colony-stimulating factor-treated mice. Blood 2001; 98 : 3520-3526.

25. Asselin-Paturel C, Boonstra A, Dalod M, Durand I, Yessaad N, Dezutter-Dambuyant C et al. Mouse type I IFN-producing cells are immature APCs with plasmacytoid morphology. Nat Immunol 2001; 2: 1144-1150.

26. Spits H, Lanier LL. Natural killer or dendritic: what's in a name? Immunity 2007; 26: 11-16.

27. Shortman K, Villadangos JA. Is it a DC, is it an NK? No, it's an IKDC. Nat Med 2006; 12 167-168.

28. Bonmort M, Ullrich E, Mignot G, Jacobs B, Chaput N, Zitvogel L. Interferon-gamma is produced by another player of innate immune responses: the interferon-producing killer dendritic cell (IKDC). Biochimie 2007; 89: 872-877.

29. Chaudhry UI, Kingham TP, Plitas G, Katz SC, Raab JR, DeMatteo RP. Combined stimulation with interleukin-18 and $\mathrm{CpG}$ induces murine natural killer dendritic cells to produce IFN-gamma and inhibit tumor growth. Cancer Res 2006; 66: 10497-10504.

30. Vremec D, O'Keeffe $M$, Hochrein $H$, Fuchsberger M, Caminschi I, Lahoud $M$ et al. Production of interferons by dendritic cells, plasmacytoid cells, natural killer cells and interferon-producing killer dendritic cells. Blood 2007; 109: 1165-1173.

31. Mailliard RB, Alber SM, Shen H, Watkins SC, Kirkwood JM, Herberman RB et al. IL-18 induced CD83+CCR7+ NK helper cells. J Exp Med 2005; 202: 941-953.

32. Kalinski $\mathrm{P}$, Mailliard RB, Giermasz A, Zeh HJ, Basse P, Bartlett DL et al. Natural killerdendritic cell cross-talk in cancer immunotherapy. Expert Opin Biol Ther 2005; 5: 1303-1315.

33. Vanderheyde N, Aksoy E, Amraoui Z, Vandenabeele P, Goldman M, Willems F. Tumoricidal activity of monocyte-derived dendritic cells: evidence for a caspase-8dependent, Fas-associated death domain-independent mechanism. J Immunol 2001; 167 3565-3569.

34. Vanderheyde N, Vandenabeele P, Goldman M, Willems F. Distinct mechanisms are involved in tumoristatic and tumoricidal activities of monocyte-derived dendritic cells. Immunol Lett 2004; 91: 99-101.

35. Ullrich E, Bonmort M, Mignot G, Chaput N, Taieb J, Menard C et al. Therapy-induced tumo immunosurveillance involves IFN-producing killer dendritic cells. Cancer Res 2007; 67: 851-853.

36. Janjic BM, Lu G, Pimenov A, Whiteside TL, Storkus WJ, Vujanovic NL. Innate direct anticancer effector function of human immature dendritic cells. I. Involvement of an apoptosis-inducing pathway. J Immunol 2002; 168: 1823-1830.

37. Joo HG, Fleming TP, Tanaka Y, Dunn TJ, Linehan DC, Goedegebuure PS et al. Human dendritic cells induce tumor-specific apoptosis by soluble factors. Int J Cancer 2002; 102 $20-28$. 
38. Vidalain PO, Azocar O, Yagita H, Rabourdin-Combe C, Servet-Delprat C. Cytotoxic activity of human dendritic cells is differentially regulated by double-stranded RNA and CD4O ligand. J Immunol 2001; 167: 3765-3772.

39. Liu S, Yu Y, Zhang M, Wang W, Cao X. The involvement of TNF-alpha-related apoptosisinducing ligand in the enhanced cytotoxicity of IFN-beta-stimulated human dendritic cells to tumor cells. J Immunol 2001; 166: 5407-5415.

40. Shi J, Ikeda K, Fujii N, Kondo E, Shinagawa K, Ishimaru F et al. Activated human umbilical cord blood dendritic cells kill tumor cells without damaging normal hematological progenitor cells. Cancer Sci 2005; 96: 127-133.

41. Yang R, Xu D, Zhang A, Gruber A. Immature dendritic cells kill ovarian carcinoma cells by a FAS/FASL pathway, enabling them to sensitize tumor-specific CTLs. Int J Cancer 2001; 94: 407-413.

42. Hoves S, Krause SW, Halbritter D, Zhang HG, Mountz JD, Scholmerich J et al. Mature but not immature Fas ligand (CD95L)-transduced human monocyte-derived dendritic cells are protected from Fas-mediated apoptosis and can be used as killer APC. J Immunol 2003; 170: 5406-5413.

43. Ayres FM, Narita M, Takahashi M, Yano T, Liu A, Toba K et al. Human dendritic cells mediate anti-tumor activity against hematopoietic tumor cells without direct contact and Fas/FasL killing pathway. Oncol Rep 2004; 11: 1017-1023.

44. Hirano A, Longo DL, Taub DD, Ferris DK, Young LS, Eliopoulos AG et al. Inhibition of human breast carcinoma growth by a soluble recombinant human $C D 40$ ligand. Blood 1999; 93: 2999-3007.

45. Tong AW, Papayoti MH, Netto G, Armstrong DT, Ordonez G, Lawson JM et al. Growthinhibitory effects of CD40 ligand (CD154) and its endogenous expression in human breast cancer. Clin Cancer Res 2001; 7: 691-703.

46. Triozzi PL, Khurram R, Aldrich WA, Walker MJ, Kim JA, Jaynes S. Intratumoral injection of dendritic cells derived in vitro in patients with metastatic cancer. Cancer 2000; 89 2646-2654.
47. Melief CJ. Mini-review: regulation of cytotoxic $T$ lymphocyte responses by dendritic cells: peaceful coexistence of cross-priming and direct priming? Eur J Immunol 2003; 33: 2645-2654.

48. Harshyne LA, Zimmer MI, Watkins SC, Barratt-Boyes SM. A role for class A scavenger receptor in dendritic cell nibbling from live cells. J Immunol 2003; 170 : 2302-2309.

49. Goldszmid RS, Idoyaga J, Bravo Al, Steinman R, Mordoh J, Wainstok R. Dendritic cells charged with apoptotic tumor cells induce long-lived protective CD4+ and CD8+ T cell immunity against B16 melanoma. J Immunol 2003; 171: 5940-5947.

50. Chaudhry UI, Katz SC, Kingham TP, Pillarisetty VG, Raab JR, Shah AB et al. In vivo overexpression of Flt3 ligand expands and activates murine spleen natural killer dendritic cells. FASEB J 2006; 20: 982-984.

51. Pirtskhalaishvili G, Shurin GV, Esche C, Cai Q, Salup RR, Bykovskaia SN et al. Cytokine-mediated protection of human dendritic cells from prostate cancer-induced apoptosis is regulated by the $\mathrm{Bcl}-2$ family of proteins. $\mathrm{Br} J$ Cancer 2000; 83: 506-513.

52. Pinzon-Charry A, Maxwell T, McGuckin MA, Schmidt C, Furnival C, Lopez JA Spontaneous apoptosis of blood dendritic cells in patients with breast cancer. Breast Cancer Res 2006; 8: R5.

53. Prins RM, Craft N, Bruhn KW, Khan-Faroogi H, Koya RC, Stripecke R et al. The TLR-7 agonist, imiquimod, enhances dendritic cell survival and promotes tumor antigen-specific $T$ cell priming: relation to central nervous system antitumor immunity. J Immunol 2006; 176 : 157-164.

54. Park Y, Lee SW, Sung YC. Cutting Edge: CpG DNA inhibits dendritic cell apoptosis by upregulating cellular inhibitor of apoptosis proteins through the phosphatidylinositide $-3^{\prime}-\mathrm{OH}$ kinase pathway. J Immunol 2002; 168: 5-8.

55. Banchereau J, Briere F, Caux C, Davoust J, Lebecque S, Liu YJ et al. Immunobiology of dendritic cells. Annu Rev Immunol 2000; 18: 767-811. 